\title{
Ergonomic assessment among radiology technologists: a survey in a hospital
}

\author{
Pais, Fernando Lima ${ }^{\mathrm{a}}$; Azevedo, Paulo Roberto ${ }^{\mathrm{b}}$; Medeiros, Lícia Helena de Oliveira ${ }^{\mathrm{c}}$, Freitas, Iraí \\ Borges de ${ }^{\mathrm{d}}$ and Stamato, Cláudia ${ }^{\mathrm{e}}$. \\ ${ }^{a}$ Specialization Student, Ergonomics, PUC-Rio; fernando@okidorio.com \\ b Specialization Student, Ergonomics, PUC-Rio; paulllor@oi.com.br \\ ${ }^{\mathrm{c}}$ Master of Science, Human Motricity Science, UCB; liciaomedeiros@hotmail.com \\ 'Specialist, Workers' Health and Human Ecology, ENSP-FIOCRUZ; irai.borges@gmail.com \\ ${ }^{\mathrm{e}}$ Master of Science, Design, PUC-Rio; stamatoclaudia@gmail.com
}

\begin{abstract}
This article is the result of an Ergonomic Diagnosis in a study for a Specialization Course in Ergonomics. The research is being done in a public hospital in the city of Rio de Janeiro, where the target system is the radiology sector. For diagnosis purposes, subjective techniques were used, such as an open-ended survey, Corlett questionnaire and techniques for evaluating ergonomic risk such as Owas and Rula. Systematic observation was emphasized using photos and films. Preliminary observations made to the radiographers found that these professionals suffer risks of physical and verbal harassment, as well as sexual harassment. Most of them feel discriminated against in terms of race and accumulate activities demanding a lot of attention, as the medical diagnosis and subsequent procedures will depend on the outcome of this task. They accumulate tension due to the weight of responsibility, since there are cases where the patient has risk of death.
\end{abstract}

Keywords: Ergonomic Diagnosis, radiology sector, ergonomic assessment

\section{Introduction}

This article presents the results of Ergonomic Diagnosis performed in the radiology center of a Local Hospital in Rio de Janeiro. The overall objective is to identify, through postural assessment, the relationship between the discomfort reported and postural constraints of radiographers from the standpoint of ergonomics. With the systematic observations made, and the answers of a questionnaire, the study was started in order to improve working conditions in the target sector.

The Local Hospital in Rio de Janeiro, chosen for this study, has a radiology center consisting of three examination rooms, a darkroom, a camera lucida, a dormitory a reporting room. It has 39 radiographers, including 13 females and 26 males, who take 7,000 radiologic images per month, with about 150 patients a day. The work is done in weekly shifts. Each shift lasts 24 uninterrupted hours by 144 hours of rest.

It is observed the conditions of those professionals working in this sector and the man/machine interactions. It is analyzed the tasks performed in order to check whether there are awkward postures occur in the workplace.

"The hospital environment is conducive to health risks to everyone working in this environment due to alternate shifts, contact with patients, contaminated materials, depression and constant source of stress. Many postural constraints are acquired during the use of equipment and furniture in the hospital environment" [6].

"Stress at work is defined as the misalignment between the task conditions and the conditions of individual workers as the harmful physical and emotional responses arising when the work demands are not in balance with the capabilities and resources of workers" [2].

The profile of tasks requires constant static work where the user adopts inappropriate postures and performs strength against gravity, remaining in that position for long periods, as well as an exhaustive 
workload demanding high levels of responsibility. The task combines the following activities: taking the request for examination, identifying the patient, walking them to the examination counter, picking up the chassis, placing the patient and identifying the radiographic film number, adjusting the technique and irradiating it, transporting the chassis to the camera lucida, assessing the quality of the image and releasing the patient.

The static work that involves the task of radiographers has the following inappropriate postures: work involving trunk rotation and lifting of the arms, hip flexion, standing for long periods without rest, use of force to hold equipment and handling heavy and unconscious patients.

Firstly, the Ergonomic Assessment consisted of a Non-systematic Observation of the task performed by the users in their work environment, which identified the chemical and environmental toxicity and contagion problems related to the exposure to biological agents especially while handling patients with open wounds, sterilizing equipment and materials, hygiene and healthy conditions of the center concerned.

During this stage, eight radiographers, out of 39 radiographers who work at the hospital, answered a questionnaire. That data survey consisted of closedended questions including: personal data, cognitive ergonomics and organizational ergonomics. The questionnaire was answered at the workplace, in a private room after working hours.

The themes related to cognitive ergonomics were: repetition of work, monotony, accumulation of tasks, definition of work methods, time for completing the task, steadiness of attention, variety and cycle of duties, degree of tension to perform the task, impaired health after working hours. Organizational ergonomics included the following: workload, communication and line management support; quality of the job; suggesting changes in the work environment, tools and discomfort. Environmental ergonomics included the following items: noise, thermal comfort and lighting in the workplace.

Each radiographer answered a questionnaire of 15 questions. They were free to identify themselves or not. All of them preferred to remain anonymous.

With regard to personal issues, $90 \%$ of respondents said that in their work they are exposed to the risk of verbal abuse, and the same percentage reported sexual harassment. As to discrimination, $65 \%$ of respondents reported being discriminated against in terms of race and $55 \%$ did not perceive discrimination as to age.
On the subject of cognitive ergonomics, all respondents consider that the work they do is not repetitive. All respondents claimed that there is an accumulation of daily activities. Out of the eight respondents, $70 \%$ of them say they have freedom of choice and all agree that the activity requires constant attention. $90 \%$ say they are tense while performing the task and believe that health is impaired due to working hours.

On the subject of organizational ergonomics, three employees do not believe in the possibility of improving the quality of work. Five of them believe in that possibility. On the question of whether to participate in giving suggestions on changes in their jobs, three employees make suggestions on changes in the workplace, one of them does not make any suggestions, three of them makes suggestions once in a while.

On the question of the quality of the tools used to perform their tasks, one employee finds it good, one finds it reasonable and five consider it poor. Four employees said they needed help to carry out their work; three said they do not need any help and one said he/she needed help occasionally.

"On very low work counters, the backs are burdened by excessive trunk curvature, leading to the onset of back pain. For this type of constraint to be avoided, it is necessary that the height of work surfaces be aligned to the anthropometric measures of the radiographer for both tasks performed standing and sitting" [4].

"The problems arising from static work may appear due to the maintenance of the body in an inappropriate or unnatural posture, or when the postures are held for long periods. Muscles subjected to a static muscle contraction (isometric contraction) will suffer a decreased vascularization by strangulation of the small blood capillaries and, consequently, a decrease in the metabolic intake from sugar burning, resulting from the cellular work done to maintain static contraction" [7].

According to the non-systematic observations, registration, questionnaires and interviews, there are two problems that generate a lot of discomfort and pain at the end of a workday. The first one is related to hyperflexion of the hip and spine (exceeding the physiological limit) in order to set the numerator in the chassis (radiographic film) to identify the patient. This is due to the lack of a furniture support at an appropriate height for performing the activity, see fig. 1. Another problem consists in turning the control panel one, see fig. 4 . 


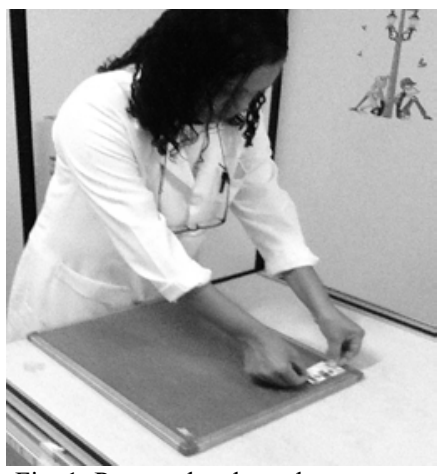

Fig. 1: Poor and awkward posture

\section{Methodology}

After the assessment, we carried out with the ergonomic diagnosis with systematic observations by using several tools: diachronic record of temporal frequency of the event, Corlett map of body segments, structured interviews and the posture assessment methods RULA (Rapid Upper Limb Assessment) and OWAS (Ovaco Working Posture Analyzing System).

\subsection{Map of body segments - Scale of discomfort/pain}

It is a psychophysical evaluation technique (biomechanics) that aims to map the presence of discomfort/pain felt among the participants, i.e., they should subjectively mark on a scale the level of discomfort/pain according to the subdivision of the existing body segments in a pre-established human figure.

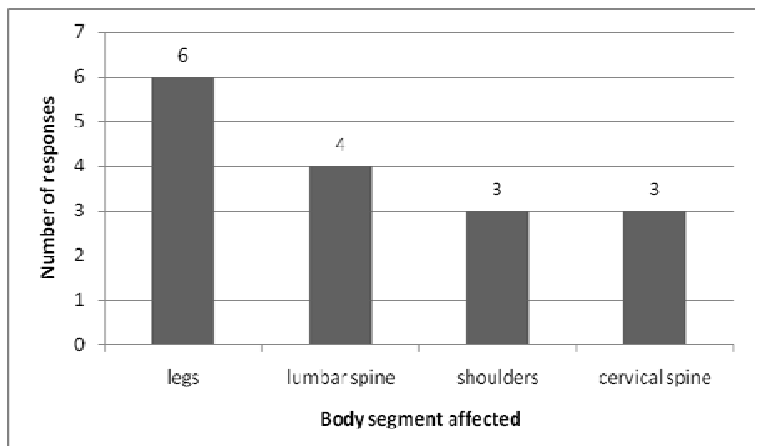

Fig. 2: Charts on the percentage of users who report pain and discomfort in the routine of their work.
The method was applied to quantify the body discomforts after one day of work consisting of a $24 \mathrm{~h}$ shift of completed by the radiographers [5]. The radiographers were asked about the body segments in which they felt more pain. The most affected body segments were the legs and lower back, as shown in Fig. 2.

\subsection{The RULA method}

It is a fairly quick tool that assesses biomechanical overload of the upper limbs and neck while in an occupational task. The main result is intended to identify the need for a deeper analysis of the risk with other methods, so it is an instrument of generic research [5]. The ergonomic risk factor in this method is represented by the postures assumed by workers in their working day. The risk assessment is made from a systematic observation of work cycles scoring postures, frequency and strength on a scale ranging from 1 (a), corresponding to the movement or posture at work where the risk factor is minimum, up to 9 (nine) where the risk factor is maximum.

\subsection{The OWAS method}

This method was developed in Finland to examine the work postures in the steel industry and was proposed by the Finnish researchers Karku, Kansas and Kuorinka in 1977 to Ovaco Oy Company. The researchers defined seventy-two typical postures that resulted from different combinations and conducted more than thirty-six thousand observations in fiftytwo activities to test the method. The method requires that the task be observe as a whole to select the positions to be analyzed. It is based on sampling of activities in constant or variable intervals, checking the frequency and time spent in each posture. The samples consider the postures of the back, arms, legs, use of force and the phase of activity.

After collecting the data, a six-digit code is determined for a scale ranging from one (1), which is an acceptable condition both for the posture and for the application of force, to seven (7), the worst condition for the lower limbs. After the mapping step, the values are compared against a table to get the final result indicating the determination of the risk level.

After determining the level of risk, the final result indicates the category of action to be taken. We analyzed four positions repeatedly adopted in the task 
of a radiographer (according to the result of the diachronic record of temporal frequency of the event).

In the postural analysis of trunk and spine flexion, setting the numerator in the chassis was observed in OWAS and in the RULA action level three (3), as shown in Table 1. Thirty-nine repetitions were presented in the diachronic record of temporal frequency of the event. In the postural analysis of trunk and cervical spine flexion, in setting the control panel, the result through the OWAS and RULA tools was three. In the diachronic record of frequency, there were 35 repetitions.

In the postural analysis of patient preparation in the vertical bucky, we observed in OWAS and in the RULA action level four (4), and in the diachronic record of temporal frequency of the event, there were 50 repetitions.

In the postural analysis of patient preparation in the horizontal bucky, we observed in OWAS and in the RULA action level two (2), and in the diachronic record of temporal frequency of the event, there were 18 repetitions.

Table 1

Levels of action and the OWAS and RULA methods

\begin{tabular}{|l|l|}
\hline $\begin{array}{l}\text { Action } \\
\text { level }\end{array}$ & Definition \\
\hline 1 & Changes are needed in the LONG term. \\
\hline 2 & Changes are needed in the MEDIUM term. \\
\hline 3 & $\begin{array}{l}\text { Further studies are needed and changes will be } \\
\text { required in the near future, in the SHORT term. }\end{array}$ \\
\hline 4 & $\begin{array}{l}\text { Further studies are needed and changes will be } \\
\text { required immediately, VERY SHORT term. }\end{array}$ \\
\hline
\end{tabular}

\section{Improvement projects}

Considering the demands presented, some projects were validated with a view to improve ergonomic conditions in the radiology sector.

- 1. Design of a support for fixing the numerator in the chassis.

- 2. Design of a support for the control panel under the plumbiferous glass to allow viewing the crosshead in the patient.

- 3. Implementation of kinesiotherapy at work.

\subsection{Designing a support for fixing the numerator in the chassis.}

After completing the diagnosis, in order to minimize the risk of injury due to hip and cervical spine hyperflexion in the setting the numerator in the chassis, we designed a support an appropriate angles and heights for increasing comfort to the neck/torso of the user as shown in Fig. 3.

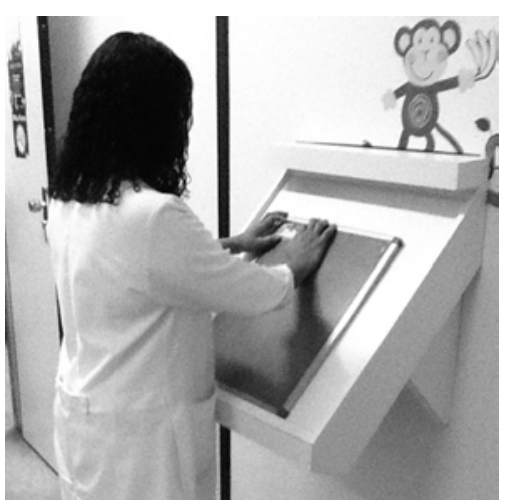

Fig. 3: New support

The design requirements raised for the support were:

- Chassis and numerator of radiographic film at eye level.

- Foot space.

- Counter to support the chassis and the numerator.

- Accommodation area pre-defined by extreme anthropometric measures (percentiles).

To meet these requirements, some aspects were considered relevant to the design of the support: the visual field at the lateral/sagittal level with flexion of the neck, the depth to accommodate the feet, leg height higher than the ground. Besides this, the chassis and the numerator should be arranged in a way to respect the physiological angle of elbows at $90^{\circ}$ without abduction of the arms.

The height of the support table, $1.35 \mathrm{~m}$, was chosen after a satisfaction survey conducted with ten radiographers, and the measure chosen by the majority (five men and four women). The only woman who preferred a $1.30 \mathrm{~m}$ height was the one with a lower percentile, with a height of $1.55 \mathrm{~m}$. Yet, 
out of ten radiographers, eight radiographers (five men and three women) reported being very satisfied and two radiographers (two women) reported being satisfied.

\subsection{Design of a support for the control panel}

To solve the problem of hyperflexion of the cervical spine in the control panel, because of excessive lateralization of the trunk, head and neck to view the crosshead (central focus) in the patient, we designed a support for the control panel which allows viewing the crosshead in the patient (informational/interfacial).

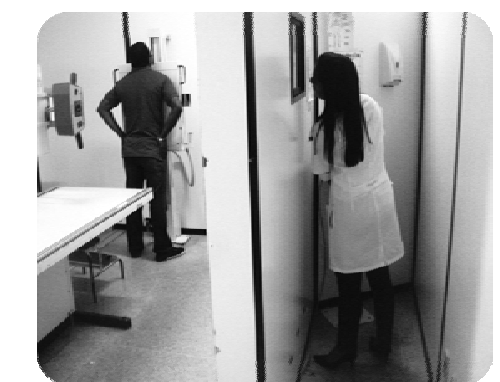

Fig. 4: Inappropriate and awkward posture

For the design of a new control panel, we calculated and defined the height according to the anthropometric measurements of the tallest man and the shortest woman. Thus, the fixation for the control panel was $135 \mathrm{~cm}$ in height from the ground up to the control keys, causing the radiographer to stand without inclining the trunk, with an elbow angle at $45^{\circ}$ and $0^{\circ}$ in the wrist joint.

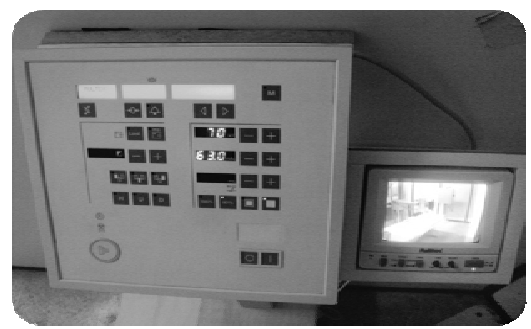

Figure 5: Control panel with display.

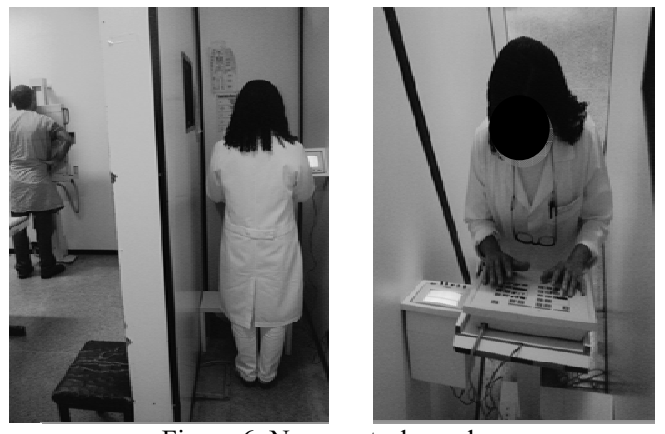

Figure 6: New control panel.

It was necessary to install a camera and a display for better viewing the radiographic focus on the patient. Therefore, a support was added to the control panel for the display.

The design was validated through a satisfaction survey using the Likert scale, where $100 \%$ (ten radiographers) were very pleased with the new control panel with a display attached.

\subsection{Kinesiotherapy at work project}

Physical training is intended to prepare the individuals to occupational demands, thereby reducing the effects of excessive work on the body [6].

The literature advocates the term "kinesiotherapy at work with the conceptualization of the term as the treatment through movements at the workplace (...) a tool intended to prevent and treat potential workrelated musculoskeletal disorders, as well as occupational diseases directly related to the musculoskeletal system"[1].

The movements that stimulate the isometric contraction of the antagonist muscle group have been proposed in order to avoid shortening of the muscle spindles.

In the hyperflexion of the neck, the discomfort will be higher the greater the number of repetitions demanded by the task, overloading the joints of the cervical spine.

With the data collected, $100 \%$ of users reported pain and discomfort in any part of the body: legs $37 \%$, lumbar spine $25 \%$, shoulder $19 \%$ and cervical spine $19 \%$ [5].

Ergonomic diagnosis assessed the following inappropriate postures: work involving twisting the 
trunk forward and sideways for 24 hours; holding objects with hands constantly, manipulations that require the arm to remain raised above shoulder level; standing over long periods of time; pushing and pulling heavy objects; hyperflexing the neck.

Depending on the results from the diachronic record of frequency (50 repetitions), postural analysis of patient preparation in the vertical bucky, as well as in OWAS and RULA, whose action level four (4) shows the need for change in the near future in the very short term, it was decided to implement the kinesiotherapy at work project as, although the equipment e available are outdated, they cannot be replaced by modern equipment in the short term.

The project consists of movements that take place before starting work and other movements throughout the day. The first one aims to prepare the individuals by stretching the following muscle groups for 10 minutes: head, shoulder, elbow, wrist and leg joints.

The second movement is compensatory and lasts 15 minutes. It aims to prevent accumulation of tensions, and proposes specific movements in the following muscle groups: shoulder girdle, shoulder extensors, elbow, wrist, legs and paravertebral muscles. Since overload occurs in the extensor muscles, we propose compensation to the extensor muscles with isometric contractions.

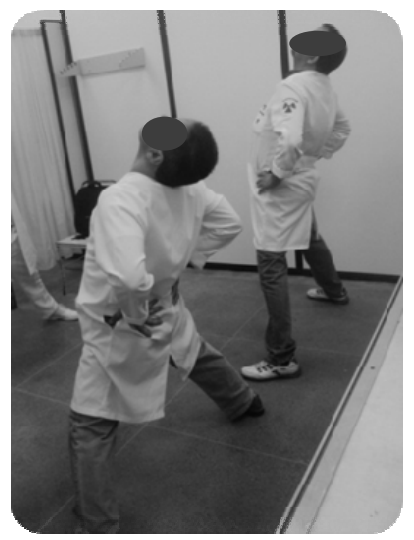

Fig. 8: Kinesiotherapy at work

\section{Concluding remarks}

These projects are incorporated into the routine work of radiographers.
By using the furniture installed (see fig. 3), so that the radiographers identify the patient in the relevant radiographic film, there were the following improvements:

- The radiographers maintain a straight back, without running the risk of injury, rather than adopting the previous position, where they had a thoracic and cervical hyperkyphosis and cervical (see fig. 3).

- The radiographers now have customized furniture for the task. Before, they would use a stretcher, which the patients use to lay down.

- This allows a better view and manipulation with support, reducing the possibility of misidentifying the patient.

The newly designed control panel (see fig. 6) provided:

- Improved posture of radiographers while viewing the procedure (see fig. 6).

- Effective view of patient's body segment to be X-rayed.

- Improvement of oral communication between the radiographer and the patient, preventing that the radiographer spends time repeatedly repositioning the patient to focus the crosshead.

As the existing equipment would not be quickly replaced by modern facilities, kinesiotherapy at work was then planned. Kinesiotherapy at work was well received, although it is not the final solution. New studies related to these management problems can be performed.

The kinesiotherapy at work is expected to raise the radiographers' awareness so that they have greater body flexibility in order to prevent aches and pains at the end of the day.

Finally, the following is recommended:

- Expanding the implementation of the projects executed into other rooms in the radiology center of HMLJ.

- Creating an ergonomics committee.

- Promoting educational lectures on ergonomics.

- Set up new sterilization methods.

- Holding regular meetings with the board.

There is need for continued project and implementation of new studies, expanding into other hospitals in Rio de Janeiro. 


\section{References}

[1] C. M. Zilli. Manual de Cinesioterapia/Ginástica Laboral: Uma tarefa interdisciplinar com ação multiprofissional. São Paulo: Lovise, 2002, pp. 57.

[2] D. Baker and R.A. Karasek. Occupational Health: recognize and preventing work-related disease and injury. 4ed Philadelphia Williams f Wwilkins, 2000

[3] H. J. C. G. Coury. Trabalhando sentado - manual para posturas confortáveis. São Carlos: EDUFCar, 1995. 2a ed. 88p

[4] K Kroemer and E. Grandjean. Manual de ergonomia: adaptando o trabalho ao homem. $5^{\circ}$ ed., Porto Alegre: Bookmam, 2005.
[5] N. Corlett. RULA: A survey method for the investigation of work-related upper limb disorders, "Applied Ergonomics" 1993.

[6] R. L. Diniz and A. de Moraes. A atuação da ergonomia em prol do trabalho cirúrgico, in: ABERGO'99. Anais. Salvador, 1999.

[7] S. Lancman. Saúde, trabalho e terapia ocupacional. São Paulo: Roca, 2004 